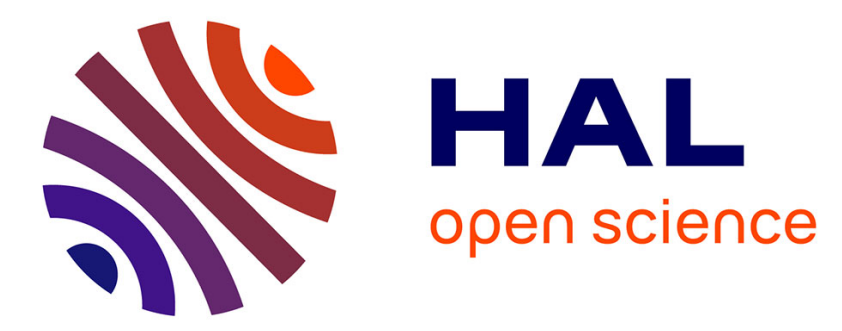

\title{
On the modelling of the direct bonding of two silicon surfaces
}

\author{
Natacha Cocheteau, Frédéric Lebon, Iulian Rosu, Aurelien Maurel-Pantel, \\ Sonia Ait Zaid, Isabelle Savin de Larclause
}

\section{- To cite this version:}

Natacha Cocheteau, Frédéric Lebon, Iulian Rosu, Aurelien Maurel-Pantel, Sonia Ait Zaid, et al.. On the modelling of the direct bonding of two silicon surfaces. Eleventh International Conference on Computational Structures Technology, Sep 2012, Dubrovnik, Croatia. 10.4203/ccp.99.143 . hal00740761

\section{HAL Id: hal-00740761 \\ https://hal.science/hal-00740761}

Submitted on 19 Nov 2021

HAL is a multi-disciplinary open access archive for the deposit and dissemination of scientific research documents, whether they are published or not. The documents may come from teaching and research institutions in France or abroad, or from public or private research centers.
L'archive ouverte pluridisciplinaire HAL, est destinée au dépôt et à la diffusion de documents scientifiques de niveau recherche, publiés ou non, émanant des établissements d'enseignement et de recherche français ou étrangers, des laboratoires publics ou privés. 


\title{
On the modeling of two bonded silicon surfaces
}

\author{
N. Cocheteau *, A. Maurel-Pantel *, F. Lebon *, I. Rosu *, S. AitZaid ${ }^{+}$, I. Savin \\ DeLarclause $^{+}$ \\ *LMA, Mechanics and Acoustics Laboratory, CNRS, UPR 7051, Aix-Marseille Univ, Centrale \\ Marseille, 31, Chemin Joseph Aiguier, F-13402 Marseille Cedex 20, France \\ e-mail: cocheteau/maurel/lebon/rosu@lma.cnrs-mrs.fr \\ ${ }^{+}$CNES, National Center for Spatial Studies, 18 Avenue Édouard Belin 31400 Toulouse, France \\ e-mail: Sonia.AitZaid/Isabelle.SavinDeLarclause@cnes.fr
}

\begin{abstract}
Direct bonding is a well-known process. However in order to use this process in spatial instrument fabrication the mechanical resistance needs to be quantified. In order to improve bonded strength, optimal parameters of the process are found by studying the influence of annealing time, temperature and roughness which are studied using three experimental methods: double shear, cleavage and wedge tests. Those parameters are chosen thanks to the appearance of time/temperature equivalence. Results brought out a predictive model of the bonding energy.
\end{abstract}

Keywords : Direct Bonding, Bonding Energy, Double Shear Test, cleavage, wedge test, process parameters, silica glasses, and Zerodur® glasses.

1. Introduction:

Direct bonding consists in joining two surfaces without the use of any adhesives $[1,2]$. Direct bonding is a process involved in micro-fabrication process on micro-electronics. The main applications are on silicon-on-insulator devices [3]. They are of particular interest to spatial instruments applications. Indeed, this is a high-precision process and assemblies obtained present a dimensional stability due to the fact that no mechanical part or glue is required and the risks of contamination associated with degassing are avoided.

This kind of process has already passed with success the mechanical and thermal environment of space [4], where the constraints involved (thermal fatigue, vibrations, etc.) are very different from those encountered on Earth. However, this is necessary to quantify the bonding strength and to improve the mechanical performance of adhesive bonds without degrading optical performances of the material used.

In this paper we present the mechanical characterization of silica and Zerodur samples using double shear, cleavage and wedge tests and the influence of some parameters process on the mechanical strength of bonded interfaces in order to find the optimal parameters of the process.

2. Double shear tests:

Doubles shear test were performed to find optimal parameters of the process. The influence of annealing time and temperature and roughness (coupled with thermal treatment) was studied. 
Samples are constituted with two cylinders of $5 \mathrm{~mm}$ thickness and $10 \mathrm{~mm}$ diameter, and one cylinder of $5 \mathrm{~mm}$ thickness and $15 \mathrm{~mm}$ diameter bonded together.
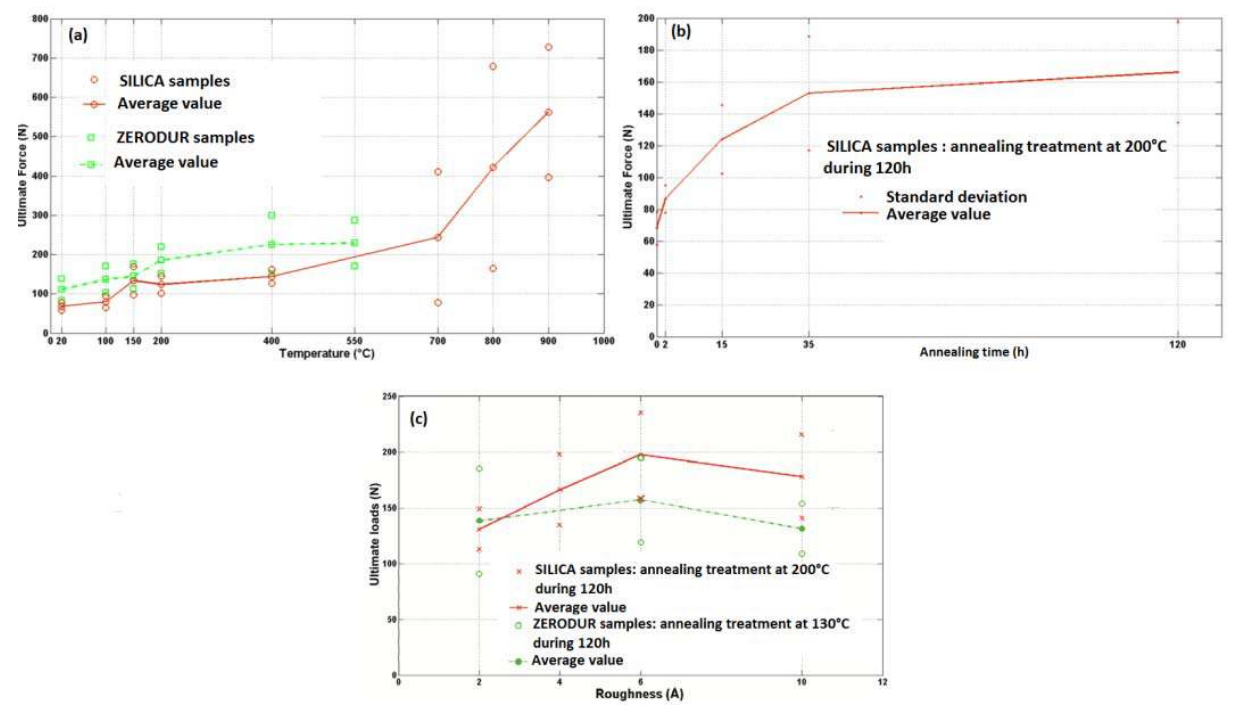

Fig. 1 : Double shear test results. Influence of annealing temperature (a), annealing time (b) and roughness coupled with thermal treatment.

Results, presents in Fig. 1a, b show a nonlinear increase of the mechanical resistance with annealing temperature and time with the appearance of a plateau for long time treatment.

Moreover, a kind of equivalence between short time treatment at high temperature and longtime treatment at short temperature is observable.

Fig.1c shows an increase of the mechanical resistance until a roughness of $0.6 \mathrm{~nm}$ RMS then a decrease for silica samples. For Zerodur samples, mechanical resistance can be supposed constant due to the dispersion of results. Results do not agree with literature [5], but samples have undergone a thermal treatment during $120 \mathrm{~h}$ at $200^{\circ} \mathrm{C}$ for silica and $130^{\circ} \mathrm{C}$ for Zerodur samples. A long time treatment promotes the formation of covalent bonds [6]. The bonding energy, thus, mechanical resistance, at this range of temperature is limited by the contacted area. We are led to believe that during this annealing treatment the area of contacted zone increases with the size of roughness until reaching a maximum before decreasing again.

Despite dispersion of the double shear test, results give a good idea of optimal parameters applying to increase the mechanical resistance of bonded interfaces. Due to the time temperature equivalence and non-agreement with literature results for roughness influence combined with manufacturing constraints (high temperature are not allowed in order to not degrade optical properties of materials and coating made on assemblies) the optimal parameters chosen are for both samples: $200^{\circ} \mathrm{C}$ during $120 \mathrm{~h}$ and a roughness of $0.4 \mathrm{~nm}$ RMS.

\section{Cleavage tests:}

Previous parameters founded using double shear tests are compared to the initial condition no thermal treatment applied on samples - using cleavage tests. Samples are constituted with two blades (40x40x10 mm) bonded together. Between each experiment, surfaces are cleaned and re-adhered (without being polished anew). 

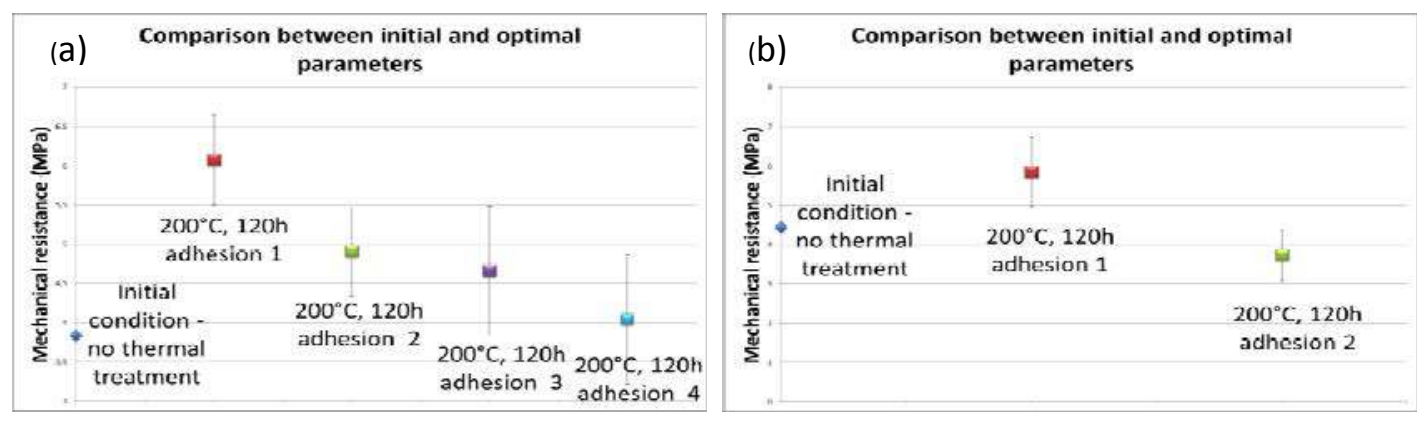

Fig. 2 : Cleavage tests: comparison between initial condition and optimal parameters for silica (a) and Zerodur (b) samples

Results presented on Fig. 2 show an increase of the mechanical resistance with optimal parameters, thus an improvement with the new parameters. Moreover, mechanical resistance slightly linearly decreased with successive adhesion/cleavage test/re-adhesion highlighting a damaging of the bonded interfaces with successive re-adhesion made in our experiments.

Results for Zerodur samples are a little worse than results for silica sample, because, samples have already undergone other treatment.

The results confirm the use of optimal parameters found to increase the mechanical resistance of samples.

\section{Wedge test:}

Important parameter to characterize direct bonding is the bonding energy. The most common method in the literature to quantify the bonding energy is the wedge test [7]. Experiments are performed on silica samples constituted with two blades $(80 \mathrm{mmx} 10 \mathrm{mmx} 500 \mu \mathrm{m})$ bonded together. In order to complete double shear tests experiments, the same influences are studied. Between each adhesion, surfaces are cleaned and re-adhered (without being polished anew).

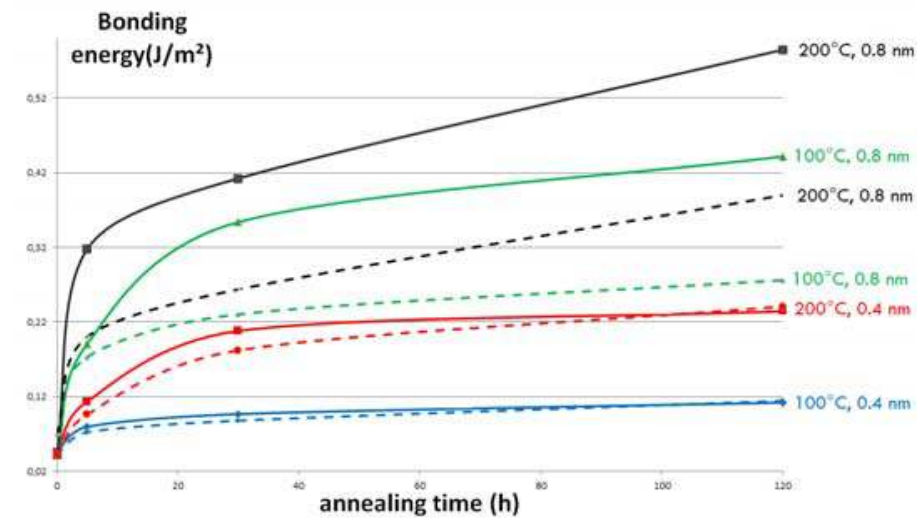

Fig. 3 : results of the wedge test, influence of annealing time, temperature and roughness (solid line: adhesion 1, dashed line: adhesion 2)

The same trends as double shear and cleavage tests are recovered: an increase of the bonding energy (W) with annealing time and temperature with appearance of a plateau and with roughness.

A predictive model of the bonding energy has also been identified using wedge test results:

$\left.W(T, t, R)=f(R)\left(W_{\max }(T, R)-W_{0}(R)\right)\left(1-e^{\left(-k_{1}(T) t\right)}\right)+W_{0}(R)\right)$ 
With $: W_{\max }(T, R)=W(t=120 h)=g(T) . \alpha(R)$

$W_{0}(R)=W($ initial condition $)=W_{0} . \alpha(R)$

$E a=65,5 \mathrm{meV}$

$\tau=3,1 \mathrm{~h}$

Where $\mathrm{f}(\mathrm{R}), \mathrm{g}(\mathrm{T})$ and $\alpha(R)$ are found using experimental results.
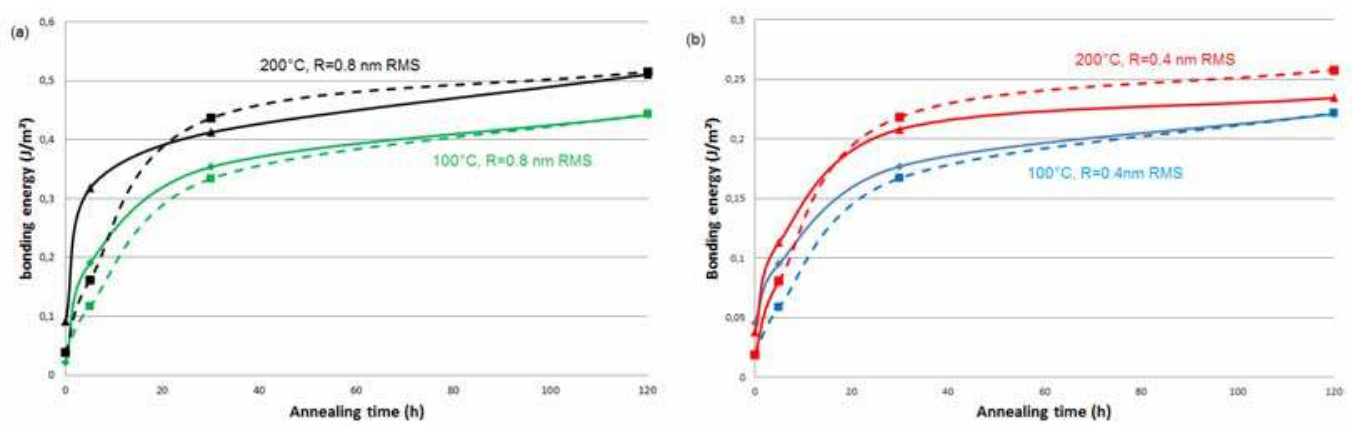

Fig. 4 : Comparison between experiments and the predictive model

\section{Conclusion:}

The three mechanical tests show the same trends results: an increase of the mechanical resistance with annealing time, temperature and with roughness (for our procedure of samples preparation). A time/temperature is observed with a phenomenon of interface damaging with successive re-adhesion. Optimal parameters of the process have been chosen and validate $\left(200^{\circ} \mathrm{C}, 120 \mathrm{~h}, 0.4 \mathrm{~nm}\right.$ RMS $)$.

A predictive model of the bonding energy has been made and need to be implemented in a finite element model in order to predict the mechanical resistance of bonded assemblies depending on process parameters.

\section{References:}

[1] Tong Q.Y., Gösele U. Semiconductor wafer bonding: recent developments. Mat. Chem. and Phys. 1994, 37:101-127.

[2] Kendall K. Molecular adhesion and its applications. Kluwer Academic Publishers; 2001.

[3] Plobl A., Krauter G. Wafer direct bonding: tailoring adhesion between brittle materials. Material Science and Engineering. 1999, R25:1-88.

[4] Pamplona T., Rossin Ch., Martin L., Moreaux G., Prieto E., Laurent P., Grassi E., Boit J.L., Castinel L., Garcia J., Milliard B. Three bipods slicer prototype: tests and finite element calculations. Proc. SPIE 7018, Advanced Optical and Mechanical Technologies in Telescopes and Instrumentation. 2008, 701828. doi: 10.1117/12.789243

[5] Cocheteau N., Lebon F., Rosu I., Maurel-Pantel A., Ait Zaid S., Savin De Larclause I. On the Modelling of the Direct Bonding of Two Silicon Surfaces, Proc. 11th Int. Conf. Comp. Struc. Tech; Dubrovnik (Croatia); 2012.

[6] Stengl R., Tan T., Gösele U. A model for the silicon wafer bonding process, Japanese Journal of Applied Physics. 1989, 28(10):1735-1741.

[7] Maszara,W.P., Goetz, G., Caviglia, A. 1988 Bonding of silicon wafers for silicon-oninsulator Journal of Applied Physics 64 4943-4950 